\title{
Effects of Cinnamon, Thyme and Turmeric Infusions on the Performance and Immune Response in of 1- to 21-Day-Old Male Broilers
}

\section{-Author(s)}

Sadeghi GH

Karimi A

Padidar Jahromi SH

Azizi T

Daneshmand A

Department of Animal Science

Faculty of Agriculture

University of Kurdistan

Kurdistan, Iran.

\section{Mail Adress}

Ghorbanali.Sadeghi

Department of Animal Science

College of Agriculture, University of Kurdistan

Kurdistan, Sanandaj, P.O. Box: 416, Iran.

Tel: +98-9183717052

Fax: +98-8716660070

E-mail: ghorbanalis@yahoo.com gsadeghi@uok.ac.ir

\section{Eeywords}

Broiler, cinnamon, infusion, thyme, turmeric

\section{-Acknowledgement}

The authors are grateful to Dr. Kenneth J. Gruber at North Carolina A\&T State University, Greensboro, North Carolina for his critical and constructive reading of the manuscript

\section{ABSTRACT}

This study was conducted to investigate the effects of the replacement of drinking water by herb infusions on the performance, relative weight of internal organs, hematocrit and immune response to Newcastle disease virus of broiler chickens. A total of 540 male broiler chicks (Ross 308) were divided into five groups, corresponding to four different treatments and one control group. Treatments were replicated eight times, and the control group four times. Experimental treatments included infusions ( 5 grams per liter) of cinnamon, thyme and turmeric in equal ratios in replacement of drinking water. Experimental period lasted 21 days and all chicks were fed with a corn-soybean based diet. Results showed that all herbs infusions caused significant $(p<0.05)$ decrease in live body weight compared with the control group at 21 days of age. Mix treatment significantly decreased relative carcass weight relative to the control group $(p<0.05)$. Herbs infusions increased the relative weight of some organs. None of herb additives affected hematocrit in comparison to control group. Cinnamon and herb mix infusion significantly improved bird immune response to the NDV vaccine in comparison to the control group and those that received only turmeric infusion. When all in-water additives were compare to each other, the birds supplemented with turmeric infusion showed the worst performance and immunity. The results of this experiment suggest that these herbs infusions did not favor the performance of broiler chickens.

\section{INTRODUCTION}

The use of additives like antibiotics as growth promoters in livestock has been banned due to concerns about their residues in animal tissues and subsequent induction of bacterial resistance. Due to this concern, researchers have evaluated alternative growth promoters such as probiotics and prebiotics, which benefits to the health of the digestive tract and its habitants have been suggested (Patterson \& Burkholder, 2003). However, manufacturing these alternatives is currently costly and time-consuming and their effects have not been clearly proven. Some researchers have evaluated herbs and their essential oils. It has been shown that the dietary incorporation of herbs and their associated essential oils may provide beneficial effects on poultry performance and health due to the antimicrobial activity of their phytochemical components (Lee et al., 2004). However, other studies have not found positive effects of herbs and their related essential oils. These latter findings may be related to experimental conditions, such as hygiene and dietary agents (Lee et al., 2003).

Thyme (Thymus vulgaris), cinnamon (Cinnamomumverum) and turmeric (Curcuma longa) are herbs commonly used as spices in human food and have received considerable attention as additives in poultry 
nutrition. Several studies have reported the beneficial effects of thyme in poultry nutrition (Al-Kassie, 2009; El-Ghousein \& Al-Beitawi, 2009; Najafi \& Torki, 2010). Canan Bölükbai \& Kuddusi Erhan (2007) also showed that supplementation of layer diets with 0.1 and $0.5 \%$ thyme improved feed conversion and egg production and also reduced $E$. colifecal content. Cross et al. (2007) studied the effects of five herbs $(10 \mathrm{~g} / \mathrm{kg}$ ) or their essential oils $(1 \mathrm{~g} / \mathrm{kg}$ ) on broiler growth, digestibility, and intestinal microfloraand showed that dietary thyme oil or yarrow herb had the most positive effects on broilerperformance. Ocak et al. (2008) reported that the inclusion of $0.2 \%$ dry thyme leaves in broiler diets from 7 to 42 days of age had no significant effects on feed efficiency, growth performance, relative weight of internal organs and the relative length of the whole gut. However, the relative weight of abdominal fat was reduced.

Turmeric is a member of Zingiberacae family and contains curcumin, demethoxycurcumin, bisdemethoxycurcumin and tetrahydrocurcuminoids as active constituents (Kiuchi et al., 1993). Antioxidant, anti-inflammatory and nematocidal activities of turmeric and their relative constituents have been demonstrated (Kiuchi et al., 1993; Ammon et al., 1993; Osawa et al., 1995). Studies have shown that supplementation of broilers diets with turmeric enhance their performance (Al-Sultan, 2003; Durrani et al., 2006). However, Mehala \& Moorthy (2008) demonstrated that 0.1 and $0.2 \%$ turmeric powder used as feed additive had no significant effects on the performance and carcass yield of broiler chickens.

Cinnamaldehyde is thepredominant compound of cinnamon, and presents antimicrobial and antioxidant activity (Lee et al., 2004; Faix et al., 2009). Hernandez et al. (2004) showed that 200 ppm essential oil extract from oregano, cinnamon and pepper improved nutrient digestibility in broilers. Moreover, the antibacterial activity of cinnamaldehyde and the essential oil obtained from cinnamon leaves was demonstrated by Chang et al. (2001).

The inclusion of thoseherbs in several forms (i.e., powder, fluid extractand essential oil) in poultry diets has been the subject of several studies (Al-Sultan, 2003; Hernandez et al., 2004; Durrani et al., 2006; Mehala \& Moorthy, 2008). However, one form that has not received much attention is herbal infusion. This process iscommonly used for preparing the more delicate and aromatic parts of a plant, and the obtained components are different from those obtained from the same plant using other methods. The objective of the present study was toassess the effects of infusions of cinnamon, thyme, turmeric and their combinations as replacement for drinking water on the performance of male broilers.

\section{MATERIAL AND METHODS}

\section{Birds, diets and management}

A total of 540 newly-hatched male broiler chicks (Ross 308) were purchased from a local hatchery and randomly allocated to 36 litter-floor pens (15 birds per pen). All chicks were fed a corn-soybean based diet daily for 21 days of experimental period (Table 1). Diets were formulated to meet broiler nutrient requirements according to the Ross 308 Management Guideline (2008). Chicks were randomly distributed to one of the four treatment groups or to the control group in a completely randomized design. The experimental treatment involved the replacement of regular drinking water by herb-infused water. The four treatments were infusions ( 5 grams per liter) of cinnamon, thyme, turmeric and theircombination, which contained equal ratios ofthyme, turmeric andcinnamon). Eachtreatment was replicated eight times and the control group fourtimes. Feed, water and herb infusions were provided ad libitum and chicks had access to light according to a 23L/1D program. All chicks were vaccinated againstNewcastle disease at sevenand 17 days, by eye-drop and drinking water, respectively. Vaccination was carried out according to the regional vaccination program routine.

\section{Preparation of herb infusions}

Thyme (Thymus vulgaris), cinnamon (Cinnamomumverum) and turmeric (Curcuma longa) were purchased commercially as dry powder. The infusions were prepared daily, according to Durraniet al. (2007). The herbal powders were placed in a recipient and freshly boiled water was poured over the herbs ( 5 gramsper liter). The container was sealed and placed at environmental temperature for $8 \mathrm{~h}$. After cooling, the prepared infusion was freshly added to drinkers.

\section{Measured Parameters}

The initial and final body weight and the feed intake were weekly recorded for each group. Average daily gain (ADG), average daily feed intake (ADFI) and feed conversion ratio (FCR) werealso calculated for each treatment. Live body weight (LBW) was individually measured onday 21. In order toassess blood and carcass 
Table 1 - Ingredient and calculated nutritional composition of the diet (g per $100 \mathrm{~g}$ as fed).

\begin{tabular}{|c|c|}
\hline \multicolumn{2}{|l|}{ Ingredients } \\
\hline Corn & 56.36 \\
\hline Soybean meal & 33.79 \\
\hline Canola meal & 2.00 \\
\hline Fish meal & 3.00 \\
\hline Soybean oil & 1.47 \\
\hline Dicalcium phosphate & 1.24 \\
\hline $\mathrm{CaCO}_{3}$ & 1.10 \\
\hline Common salt & 0.31 \\
\hline Vitamin premix ${ }^{1}$ & 0.25 \\
\hline Mineral premix ${ }^{2}$ & 0.25 \\
\hline L-lysine HCL & 0.10 \\
\hline DL-methionine & 0.14 \\
\hline \multicolumn{2}{|l|}{ Calculated composition } \\
\hline Crude protein(g/kg) & 225 \\
\hline Metabolizable energy(MJ/kg) & 12.13 \\
\hline Fiber ( $g / k g)$ & 386 \\
\hline Methionine $(\mathrm{g} / \mathrm{kg})$ & 5.49 \\
\hline Total sulfur amino acids(g/kg) & 9.2 \\
\hline Lysine (g/kg) & 13.8 \\
\hline Calcium $(\mathrm{g} / \mathrm{kg}$ ) & 9.8 \\
\hline Available phosphorus $(\mathrm{g} / \mathrm{kg})$ & 4.7 \\
\hline \multicolumn{2}{|c|}{ 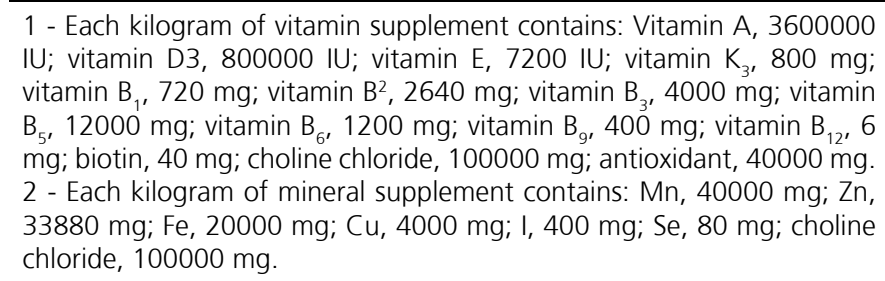 } \\
\hline
\end{tabular}

characteristics, one bird per replicate were sacrificed at 21 days of age. Blood samples were collected in two tubes, one containing EDTA for hematocrit analysis and the other to evaluate the immune response to NDV by enzyme-linked immunosorbent assay (ELISA). The clotted blood was centrifuged and the serum was separated and stored at $-24^{\circ} \mathrm{C}$ until subsequent analysis. The analysis was performed using the Newcastle Disease Antibody Test Kit from IDEXX laboratories Inc. (Westbrook, ME04092). Carcass, liver, pancreas, heart, spleen, bursa, abdominal fat, gizzard (empty), proventriculus, cecum, duodenum, jejunum and ileum as a percentage of live body weight (relative weight) relative weights and duodenum, jejunum and ileum relative lengthswere calculated.

\section{Data analysis}

The results of this study were analyzed as a completely randomized design with unequal replications by analysis of variance (ANOVA), using the general linear model (GLM) procedure of SAS (2001). Means were compared using Duncan's Multiple Range Test with accepted level of significance of0.05.

\section{RESULTS}

\section{Performance parameters}

The effects of herbal infusions on weekly performance parameters are presented in Table 2 . Individual cinnamon, thyme and turmeric infusions or their combination did not influence LBW, ADG and ADFI in comparison to the control group between 1-7 days of age $(p>0.05)$. However, during this period, turmeric-fed birds presented significantly $(p<0.05)$ higher FCR than those in the control and cinnamon groups. All herbal infusions significantly $(p<0.05)$ increased both ADFI and FCR compared with the control group between 7-14 days of age; however, LBW and ADG were not affected by these additives. In comparison with the control and cinnamon groups, the turmeric-treated group presented significantly lower $(p<0.05)$ ADG between 14-21 days of age.The other evaluated performance parameters were not affected by infusion additives for this age period. None of the herbal infusions had a significant effect on $A D G$, ADFI and FCR in comparison to control group ( $p>0.05$ ) during the entire experimental period (1-21 days of age), while all infusion additives significantly decreased LBW $(p<0.05)$.

Blood parameters and carcasses characteristics

The relative weights of the internal organs at 21 days of age are shown in Table 3. The use of a mixed infusion of additives, which contained thyme, turmeric and cinnamon, significantly decreased the weight of ready-to-cook poultry carcasses in comparison to the control group $(p<0.05)$. Thyme-treated broilers showed the highest gizzard and proventriculus relative weights relative to the control broilers $(p<0.05)$. None of the treatments significantly affected the relative weights of the liver, pancreas, heart, abdominal fat, spleen, cecum and bursa.

The relative weights and lengths of the different parts of intestine and entire small intestine are shown in Table 3. These data confirm that thyme and turmeric significantly increased $(p<0.05)$ entire small intestine weight in comparison to the control birds. Turmeric, as compared to the control group, significantly $(p<0.05)$ increased ileum weight. None of the other treatments 
Table 2 - Live body weight (LBW), average daily gain (ADG), average daily feed intake (ADFI) and feed conversion ratio (FCR) of experimental male broilers at 1-21 days of age.

\begin{tabular}{|c|c|c|c|c|c|c|c|}
\hline \multirow[t]{2}{*}{ Parameters } & \multirow[b]{2}{*}{ Age } & \multicolumn{5}{|c|}{ Treatments $^{1}$} & \multirow[b]{2}{*}{ SEM } \\
\hline & & Control & Thyme & Turmeric & Cinnamon & Mix & \\
\hline \multirow{3}{*}{ Live body weight (g) } & 7 & 144 & 141 & 140 & 145 & 139 & 1.1 \\
\hline & 14 & 336 & 324 & 320 & 334 & 326 & 2.4 \\
\hline & 21 & $725 a$ & $681 b$ & $658 b$ & $690 b$ & $675 b$ & 5.4 \\
\hline \multirow{4}{*}{ Average daily gain ( $\mathrm{g}$ ) } & $1-7$ & 14.7 & 14.2 & 14.1 & 14.8 & 13.9 & 0.15 \\
\hline & $7-14$ & 27.4 & 25.6 & 25.7 & 26.5 & 26.3 & 0.27 \\
\hline & $14-21$ & $51.5 a$ & $49.1 \mathrm{ab}$ & $47.2 \mathrm{~b}$ & $50.6 a$ & $48.6 a b$ & 0.46 \\
\hline & $1-21$ & 30.0 & 29.4 & 29.0 & 30.4 & 29.3 & 0.25 \\
\hline \multirow{4}{*}{ Average daily feed intake (g) } & $1-7$ & 19.2 & 19.1 & 19.7 & 19.3 & 18.8 & 0.16 \\
\hline & $7-14$ & $34.3 b$ & $40.1 \mathrm{a}$ & $39.3 a$ & $39.7 a$ & $38.6 a$ & 0.53 \\
\hline & $14-21$ & 78.8 & 77.2 & 74.0 & 76.7 & 75.3 & 0.69 \\
\hline & $1-21$ & 48.3 & 49.0 & 48.7 & 48.6 & 48.0 & 0.26 \\
\hline \multirow{4}{*}{ Feed conversion ratio $(\mathrm{g} / \mathrm{g})$} & $1-7$ & $1.30 \mathrm{~b}$ & $1.34 \mathrm{ab}$ & $1.40 a$ & $1.30 \mathrm{~b}$ & $1.35 a b$ & 0.012 \\
\hline & $7-14$ & $1.24 b$ & $1.57 a$ & $1.53 a$ & $1.50 a$ & $1.47 a$ & 0.022 \\
\hline & $14-21$ & 1.52 & 1.58 & 1.57 & 1.52 & 1.55 & 0.016 \\
\hline & $1-21$ & 1.61 & 1.67 & 1.68 & 1.60 & 1.64 & 0.013 \\
\hline
\end{tabular}

1- Infusion (5 grams per liter) of thyme, cinnamon, turmeric or equal ratio of their combination (mix) as replacement of the drinking water. SEM: Standard error of the mean. a,b - Means within each row followed by the same letter are not significantly different at 0.05 .

Table 3 - Relative weight and length of organs (\% of live weight) of the experimental birds at 21 days of age.

\begin{tabular}{|c|c|c|c|c|c|c|}
\hline & \multicolumn{5}{|c|}{ Treatments $^{1}$} & \multirow[b]{2}{*}{ SEM } \\
\hline & Control & Thyme & Turmeric & Cinnamon & Mix & \\
\hline \multicolumn{7}{|l|}{ Relative weight } \\
\hline Ready-to-cook carcass & $55.29 a$ & $54.90 a$ & $52.97 a b$ & $54.84 a$ & $50.51 b$ & 0.529 \\
\hline Liver & 2.72 & 2.70 & 2.87 & 3.01 & 2.77 & 0.061 \\
\hline Pancreas & 0.416 & 0.452 & 0.425 & 0.477 & 0.433 & 0.0120 \\
\hline Heart & 0.577 & 0.624 & 0.580 & 0.600 & 0.638 & 0.0135 \\
\hline Gizzard & $2.77 b$ & $3.44 a$ & $3.20 \mathrm{ab}$ & $3.01 \mathrm{ab}$ & $2.90 a b$ & 0.084 \\
\hline Proventriculus & $0.585 b$ & $0.692 a$ & $0.613 a b$ & $0.644 a b$ & $0.699 a$ & 0.0133 \\
\hline Abdominal Fat & 0.754 & 0.822 & 0.760 & 0.796 & 0.981 & 0.0499 \\
\hline Bursa & 0.278 & 0.281 & 0.246 & 0.272 & 0.300 & 0.0107 \\
\hline Spleen & 0.071 & 0.081 & 0.070 & 0.073 & 0.071 & 0.0024 \\
\hline Cecum & 0.525 & 0.545 & 0.621 & 0.598 & 0.554 & 0.0244 \\
\hline Entiresmall intestine & $4.30 b$ & $4.84 a$ & $4.89 a$ & $4.71 a b$ & 4.70ab & 0.075 \\
\hline Duodenum & 1.17 & 1.27 & 1.21 & 1.28 & 1.18 & 0.025 \\
\hline Jejunum & 1.84 & 2.02 & 2.00 & 1.85 & 2.01 & 0.045 \\
\hline Ilium & $1.29 \mathrm{~b}$ & $1.55 a b$ & $1.68 \mathrm{a}$ & $1.57 a b$ & $1.51 \mathrm{ab}$ & 0.042 \\
\hline \multicolumn{7}{|l|}{ Relative length } \\
\hline Entiresmall intestine & 25.59 & 28.24 & 27.67 & 26.04 & 27.52 & 0.458 \\
\hline Duodenum & 0.047 & 0.050 & 0.047 & 0.046 & 0.046 & 0.0009 \\
\hline Jejunum & 0.100 & 0.116 & 0.112 & 0.102 & 0.115 & 0.0024 \\
\hline Ilium & 0.109 & 0.116 & 0.118 & 0.113 & 0.114 & 0.0023 \\
\hline
\end{tabular}

1 - Infusion (5 grams per liter) of thyme, cinnamon, turmeric or equal rates of their combination (mix) as replacement of drinking water. SEM: Standard error of the means. a,b - Means within each row followed by the same letter are not significantly different at 0.05 . 
significantly influenced the relative weights and lengths of the duodenum, jejunumor entire small intestine.

The effects of the additive infusions on the immune response to the NDV vaccine and on the hematocrit are presented in Table 4. None of the herbal infusions significantly affected the hematocrit relative to the control group ( $p>0.05)$. The cinnamon and herbal mix infusions significantly improved the immune response to the NDV vaccine in comparison to the control group and those that received only the turmeric infusion $(p<0.05)$.

\section{DISCUSSION}

\section{Performance parameters}

The results of this study indicate that the use of herbal infusions as dietary supplementation toyoung male broiler chickens did not significantly improve performance parameters in comparison to control group.

The study showed that thyme suppliedas an herbal infusion did not significantly improve the performance of male broilers. This is consistent with Ocaket al. (2008), who reported that the inclusion of $0.2 \%$ thyme leaves in broiler diets had no effects on body weight gain, feed intake orfeed conversion ratio. Cross et al. (2007) also reported that the performance parameters of male broilers were not improved when their diets were supplemented with $1 \%$ thyme, whereas the results of the present study showed that thyme increased LBW and weight gain of the thyme-treated broilers. The results also agree with the findings of Mehala \& Moorthy (2008), who reported that diets supplemented with 0.1 and $0.2 \%$ turmeric had no detrimental effect on broiler performance. In contrast to this study, Durrani et al. (2006) showed that adding $0.5 \%$ turmeric to broiler diets resulted in worse ADFI and FCR both during the starter and finisher periods, but weight gain decreased only during the finisher period. Al-Sultan (2003) reported that adding 0.5\% turmeric to broilers diet improvedall their performance characteristics. Our results showed that turmeric infusion reduced live body weight more than the other evaluated infusions.
The performance of cinnamon-treated broilers was not different from those receiving the other treatments. These findings in agreement with those of Hernandez et al. (2004), who reported that the incorporation of 200 ppm of oregano, cinnamon and pepper essential oils in broilers diets had no effect on their performance at 21 and 42 days of age (Hernandez et al., 2004). Lee et al. (2003) also reported that weight gain, feed intake and feed conversion ratio were not affected by 100 ppm dietary thymol or cinnamaldehyde.

In most of the previous studies, herb powder or essential oil were added to the broiler diets, but in the present study, the aqueous extracts of these herbs was used in a different way and via drinking water Therefore, some of the inconsistencies observed in this study in comparison to others may be due to the method of preparation of the additives.

\section{Blood parameters and carcasses characteristics}

Relative weight of ready-to-cook carcasses was not affected by theherbal infusions tested in present study. However, the mixture of these herbal medicinal plants significantly reduced carcass weight $(p<0.05)$. Ocak et al. (2008) reported that broiler carcass relative weight was not affected by the inclusion of $0.2 \%$ thyme leaves in thediet. Consistent with present results, some previous studies showed that gizzard relative weight was not affected by turmeric herb or cinnamon essential oil (Durrani et al., 2006; Hernandez et al., 2004). The present data showed that thyme and turmeric increased small intestine relative weight. In addition, turmeric infusion increased ileum relative weight; however, thelength of the intestinalsectionswere not affected by the treatments. Therefore, the higher gut weights in the turmeric-treated birds may have been due to higher diameters of the gut wall that affected digestive processes, resulting in lowerlive body weight. In contrast with findings of the present study, Ocak et al. (2008) reported that no changes were detected in the gut relative weightsof broilers fed with $0.2 \%$ thyme leaves.

Cinnamon and herbal mix infusions improved antibody titers against NDV in comparison to control group. There is no published work about the effects of

Table 4 - Immune response to live Newcastle disease virus (NDV) and hematocrit percent of the experimental birdsat 21 days of age.

\begin{tabular}{lccccccc} 
& \multicolumn{5}{c}{} & Treatments & \\
& \cline { 2 - 5 } & Control & Thyme & Turmeric & Cinnamon & Mix & SEM \\
\hline Hematocrit (\%) & 32.5 & 35.6 & 34.0 & 32.6 & 32.6 & 0.62 \\
Antibody titer & $310.3 \mathrm{~b}$ & $485.1 \mathrm{ab}$ & $177.2 \mathrm{~b}$ & $529.0 \mathrm{a}$ & $767.3 \mathrm{a}$ & 0.193 \\
\hline
\end{tabular}

1 - Infusion ( $5 \mathrm{~g} / \mathrm{L}$ ) of thyme, cinnamon, turmeric or equal ratio of their combination (mix) as replacement of the drinking water. SEM: Standard error of means. $a, b$ - Means within each row followed by the same letter are not significantly different at 0.05 . 
herb infusions on antibody titers. However, Al-Ankari et al. (2004) reported that mint powder had no effects on antibody titers to NDV vaccine.

\section{CONCLUSION}

The three herb infusions (cinnamon, thyme and turmeric) used as drinking water did not improve the performance of broilers. However, cinnamon and herbal mix infusions significantly improved the immune response of birds to the NDV vaccine. When the additives were compared, the broilers supplied with the turmeric infusion presented the worst performance and immunity.

\section{REFERENCES}

Al-Ankari AS, Zaki MM, Al-Sultan SI.Use of habek mint (menthalongifolia) in broiler chicken diets. International Journal of Poultry Science 2004; 3:629-634.

Al-Kassie GAM. Influence of two plant extracts derived from thyme and cinnamon on broiler performance. Pakistan Veterinary Journal 2009; 29:169-173.

Al-Sultan SI. The effect of curcuma longa (tumeric) on overall performance of broiler chickens. International Journal of Poultry Science 2003; 2: 351-353.

Ammon HPT, Safayhi H, Mack T, Sabieraj J. Mechanism of antiinflammatory actions of curcumine and boswellic acids. Journal of Ethnopharmacology 1993; 38:113-119

Canan Bölükbai, Kuddusi Erhan M. Effect of dietary thyme (Thymus vulgaris) on laying hens performance and escherichia coli (E. coli) concentration in feces. International Journal of Natural and Engineering Sciences 2007; 1:55-58

Chang ST, Chen PF, Chang SC. Antibacterial activity of leaf essential oils and their constituents from Cinnamomumosmophloeum. Journal of Ethnopharmacology 2001; 77:123-127.

Cross DE, Mcdevitt RM, Hillman K, Acamovic T. The effect of herbs and their associated essential oils on performance, dietary digestibility and gut microflora in chickens from 7 to 28 days of age. British Poultry Science 2007; 48:496-506

Durrani FR, Ismail M, Sultan A, Suhail SM, Chand N, Durrani Z. Effect of different levels of feed added turmeric (Curcuma longa) on the performance of broiler chicks. Journal of Agricultural and Biological Science 2006; 1:9-11.

Durrani FR, Sultan A, Marri ML, Chand N, Durrani Z. Effect of wild mint (menthalongifolia) infusion on the overall performance of broiler chicks. Pakistan Journal of Biological Sciences 2007; 10:1130-1133.

El-Ghousein SS, Al-Beitawi NA. The effect of feeding of crushed thyme (Thymus valgaris L.) on growth, blood constituents, gastrointestinal tract and carcass characteristics of broiler chickens. The Journal of Poultry Science 2009; 46:100-104

Faix Š, Faixová Z, Plachá I, Koppel J. Effect of cinnamomumzeylanicum essential oil on antioxidative status in broiler chickens. Acta Veterinaria Brno 2009; 78:411-417.
Hernandez F, Madrid J, García V, Orengo J, Megías MD. Influence of two plant extracts on broilers performance, digestibility, and digestive organ size. Poultry Science 2004; 83:169-174.

Kiuchi F, Goto Y, Sugimoto N, Akao N, Kondo K, Tsuda Y. Nematocidal activity of turmeric: synergistic action of curcuminoids. Chemical and Pharmaceutical Bulletin 1993; 41:1640-1643

Lee KW, Everts $\mathrm{H}$, Beynen AC. Essential oils in broiler nutrition, International Journal of Poultry Science 2004; 3:738-752.

Lee KW, Everts H, Kappert HJ, Frehner M, Losa R, Beynen AC. Effects of dietary essential oil components on growth performance, digestive enzymes and lipid metabolism in female broiler chickens. British Poultry Science $2003 ;$ 44:450-457.

Mehala C, Moorthy M. Production performance of broilers fed with aloe vera Curcuma longa (turmeric). International Journal of Poultry Science 2008; 7:852-856.

Najafi P, Torki M. Performance, blood metabolites and immunocompetaence of broiler chicks fed diets included essential oils of medicinal herbs. Journal of Animal and Veterinary Advances 2010; 9:1164-1168.

Ocak N, Erener G, BurakAk F, Sungu M, Altop A, Ozmen A. Performance of broilers fed diets supplemented with dry peppermint (Menthapiperita L.) or thyme (Thymus vulgaris L.) leaves as growth promoter source Czech. Journal of Animal Science 2008; 53:169-175.

Osawa T, Sugiyama Y, Inayoshi M, Kawakishi S. Antioxidative activity of tetrahydrocurcuminoids. Bioscience, Biotechnology and Biochemistry 1995; 59:1609-1612

Patterson JA, Burkholder KM. Application of prebiotics and probiotics in poultry production. Poultry Science 2003; 82:627-631.

SAS Institute. SAS user's guide: statistic. Version 8.2. Cary; 2001 